\title{
Active degassing of deep-sourced fluids in central Europe: new evidences from a geochemical study in Serbia
}

\author{
PAOLO RANDAZZO ${ }^{1}$, ANTONIO CARACAUSI ${ }^{2}$, ARTHUR \\ IONESCU $^{3,4}$, WALTER D'ALESSANDRO ${ }^{2}$, LORENZA LI \\ VIGNI $^{1}$, PETER PAPIC ${ }^{5}$, GORANH MARINKOVIC ${ }^{6}$, \\ CHRISTIAN POP ${ }^{3}$, CARLO CARDELLINI $^{4}$, ALESSANDRO \\ AIUPPA $^{1}$ AND GIOVANNI CHIODINI ${ }^{2}$ \\ ${ }^{1}$ Università degli Studi di Palermo \\ ${ }^{2}$ Istituto Nazionale di Geofisica e Vulcanologia \\ ${ }^{3}$ Babes-Bolyai University \\ ${ }^{4}$ Università degli Studi di Perugia \\ ${ }^{5}$ University of Belgrade \\ ${ }^{6}$ Geological Survey of Serbia \\ Presenting Author: paolo.randazzo@unipa.it
}

Identifying the transfer of mantle-derived fluids (e.g. $\mathrm{CO}_{2}, \mathrm{~N}_{2}$, noble gases) in continental regions is critical for developing exploration strategies of natural resources (i.e., hydrocarbons, ore deposits, heat sources), and for investigating the processes shaping the deep and shallow volatiles' cycles. The outgassing of deep-mantle volatiles has recently been verified in many crustal segments of western-central Europe, but the geological/tectonic controls on deep fluid migration remain to be fully understood.

Here, we report on the results of an extensive geochemical survey of gas manifestations in the Vardar zone (Serbia, Europe), a mega-suture zone between Eurasia and Africa plates. Based on their chemical compositions $(\mathrm{C}, \mathrm{He}, \mathrm{Ne}, \mathrm{Ar})$, the studied gases are clustered into three distinct groups $\left(\mathrm{CO}_{2^{-}}, \mathrm{N}_{2^{-}}\right.$and $\mathrm{CH}_{4^{-}}$ dominated). The He isotope ratios, ranging from 0.08 to $1.19 \mathrm{Ra}$, identify a weak $(<20 \%)$ but persistent regional mantle-derived component, with the lowest ${ }^{3} \mathrm{He} /{ }^{4} \mathrm{He}$ values reflecting radiogenic He production from nearby granitoid intrusions. The $\delta^{13} \mathrm{C}$ values range from -20.2 to $-0.1 \%$, with the more negative compositions being observed in $\mathrm{N}_{2}$-dominated samples. The combined analysis of $\mathrm{He}$ and $\mathrm{C}\left(\mathrm{CO}_{2}\right)$ abundances and isotopic composition demonstrates that the main processes controlling the chemistry of the outgassing volatiles are 1) mixing between crustal and mantle-derived volatiles and 2) the partial dissolution of volatiles in groundwater. Finally, we estimate the mantle He flux at $9.0 \mathrm{x}$ $10^{9}$ atoms $\mathrm{m}^{-2} \mathrm{~s}^{-1}$, or up to 2 orders of magnitude higher than the typical fluxes in stable continental areas, suggesting a tectonic control of fluid migration through the crust. 